\title{
Bulanık kurallara ve kenar devamlılığ 1 kurallarına dayalı kenar tespiti iyileştirilmesi
}

\author{
Fatih KARA $^{1 *}$, Mustafa ULUTAŞ ${ }^{2}$ \\ ${ }^{1}$ Artvin Çoruh Üniversitesi Artvin Meslek Yüksekokulu Bilgisayar Teknolojileri Bölümü, Seyitler \\ Yerleşkesi, Artvin. \\ ${ }^{2}$ Karadeniz Teknik Üniversitesi Mühendislik Fakültesi Bilgisayar Mühendisliği Bölümü, Trabzon.
}

Geliș Tarihi (Recived Date): 17.04.2017

Kabul Tarihi (Accepted Date): 01.08.2017

\section{Özet}

Bu çalışmada tuz ve biber gürültüsü eklenmiş gri seviyeli sayısal görüntülerde bulanık kurallara (BK) ve kenar devamlıliğ kurallarına (KDK) dayalı kenar tespiti yapılması amaçlanmıştır. Bu yöntem yüksek gürültü oranl görüntülerde diğer birçok yöntemden daha iyi sonuç vermektedir. Bulanık üyelikler maksimum entropi değerine göre belirlenmektedir. Görüntünün sinyal gürültü oranı hesaplanmış ve bu orana göre kenar devamlılı̆̆ kurallarının durulaştırılması ile bulanık kuralların durulaştırılması arasında seçim yapılmıştır. Parametreye ihtiyaç duymayan bu yöntem Canny, Roberts ve Sobel yöntemleriyle karşılaştırılmıştır. Kenar devamlılığı kurallarının sürece dâhil edilmediği durumlarda programın çalışma süresinin azaldığı gösterilmiştir.

Anahtar Kelimeler: Bulanı üyelik, kenar, sinyal gürültü oranı.

\section{Improvement of edge detection based on fuzzy rules and edge continuity rules}

\begin{abstract}
\footnotetext{
*Fatih KARA, fatihkara@artvin.edu.tr, http://orcid.org/0000-0002-7467-4169

Mustafa ULUTAŞ, ulutas@ktu.edu.tr, http://orcid.org/0000-0001-8876-9591
}

In this study it was intended to do edge detection based on fuzzy rules (FR) and edge continuity rules (ECR) in salt and pepper noise added gray level images. This method has better results than other methods in high level noise ratio images. Fuzzy memberships are determined according to maximum entropy value. Image signal to noise ratio has been computed and the choice is made between fuzzy rules defuzzification and edge continuity rules defuzzification according to this ratio. This method that does not need parameters has been compared with Canny, Roberts and 
Sobel operators. It has been shown that program run time decreased in situations that edge continuity rules is not included in the process.

Keywords: Fuzzy membership, edge, signal noise ratio.

\section{Giriş}

Gürültü azaltma işlemi görüntü işleme sürecinde görüntülerin kalitesini iyileştirmek için genellikle bir ön aşama olarak kullanılmaktadır [1]. Görüntülerde bozulmalara yol açan gürültü çeşitlerinden birisi de tuz ve biber gürültüsüdür. Kameraların algılayıcılarında oluşan hatalı pikseller, bellekte saklanan verilerdeki bozulmalar tuz ve biber gürültüsüne neden olmaktadır. Tuz ve biber gürültüsünde piksellerin gri seviyesi çevrelerinden oldukça farklılaşmaktadır [2]. Tuz ve biber gürültüsünün giderilmesinde lineer olmayan yöntemler sıklıkla kullanılır [3]. Tuz ve biber gürültüsüne metin içeren görüntülerde sık rastlanmaktadır [4]. Metin içeren görüntülerdeki gürültü için önerilen kFill yönteminde komşu piksel değerlerine dayalı olarak merkez ON veya OFF durumuna dönüştürülmektedir. Böylece gürültü giderilmektedir. Gürültü bileşenlerinin bir pikselden fazla olduğu durumlarda ise geliştirilmiş kFill algoritması önerilmektedir [5]. Gürültüyü gidermek için kullanılan maksimum ve minimum filtreler de sıralama ilkesine dayalı olarak çalışmaktadır. Maksimum filtrede sıralanmış piksel değerlerinin en büyüğü seçilirken, minimum filtrede en küçük değer seçilmektedir. Bu filtrelerde en az detay kaybı ile birlikte iyi sonuç verilmektedir [6]. Yaygın gürültü giderme yöntemlerinden birisi de median filtrelemedir. Lineer olmayan median filtrelemede, boyutu belirli bir pencere içindeki gri seviyelerin değerleri sıralanmakta, ardından orta değer bulunmaktadır. Median filtreleme düşük oranlardaki tuz ve biber gürültü seviyelerinde iyi sonuç vermektedir [7]. Gürültü oranı \%40 iken standart median filtreleme iyi sonuç vermemektedir [8]. Bu sorunun çözülebilmesi için faklı yöntemler geliştirilmiştir. Progressive Switching Median (PSM) filtrede, Extremum Median (EM) filtrede, Adaptive Median (AM) filtrede ve Weighted Median (WM) filtrede pikseller sinyal ve gürültü sınıflarına ayrılmış ve olumlu sonuçlar elde edilmiştir. Gürültü seviyesi \%80 olduğu durumlarda ise bahsedilen Median filtreler yetersiz kalmaktadır. Buna çözüm olarak yerel bilgiye dayanan; gürültü seviyesini düşük, orta ve yüksek şeklinde sınıflandıran bir yöntem önerilmiştir [8]. Bu yöntem yüksek gürültü oranına sahip görüntülerde iyi çalışmaktadır. Gürültü seviyesi çok yüksek görüntülerde oldukça iyi sonuçlar elde edilen ve bulanık mantık kurallarının kullanıldığı yöntemler de mevcuttur [9-10].

Buraya kadar bahsedilen tüm yöntemlerde gürültü azaltma işlemi orijinal görüntüde değişikliğe ve bilgi kaybına neden olmaktadır. Değişikliğe uğramış görüntünün kenar bulma işlemine sokulması sağlıklı sonuç vermeyebilir. Tuz ve biber gürültüsü eklenmiş görüntüler üzerinde gürültü azaltma aşamasını uygulamadan direkt kenar bulan yöntem [2]'de anlatılmaktadır. Bulanık kenar bulma yöntemindeki amaç gürültü azaltmayı kullanmayarak orijinal görüntülerde oluşması muhtemel bilgi kaybının engellenmesi ve bozulmamış görüntü üzerinde kenar bulunmasıdır. Bu çalışmada [2]'de anlatılan yöntem için iki farklı geliştirme önerilmektedir. İki ayrı aşamada yapılan geliştirme ile daha hızlı sonuca ulaşılmaktadır. İlk geliştirme entropilerin hesaplandığı aşamadır. Entropilerin 256 farklı değer için hesaplanması oldukça uzun sürmektedir. Burada anlatılan yöntemle bu süre büyük ölçüde azaltılmaktadır. İkinci geliştirme KDK'nin sürece dâhil edilip edilmeyeceği ile ilgilidir. Sürece dâhil olması görüntülerdeki tuz ve 
biber gürültüsü oranına bağlıdır. Tuz ve biber gürültüsüne bakılmaksızın tüm görüntüler için KDK üyeliklerinin hesaplanması [2]'de anlatılmaktadır. Burada bahsedilen ikinci geliştirmeyle gürültü oranına göre KDK ile BK arasında seçim yapılmaktadır. Gürültü oranı az olan görüntülerde BK durulaştırma ile KDK durulaştırma arasında fazla fark olmamaktadır. Bu yüzden gürültü oranı düşük görüntülerde [2]'de anlatılan kuralların tümünün hesaplanmasına ihtiyaç yoktur. Sadece BK için üyeliklerin belirlenmesi daha az kural ile sonuca ulaşılmasını sağlamaktadır. Bu da çalışma süresini kısaltmaktadır.

\section{Yöntem}

Gradyan tabanlı (Roberts, Prewitt, Sobel, Canny) ve Laplace tabanlı (Marr-Hildreth, BZero Cross) kenar bulma yöntemleri gürültülü ortamlarda iyi sonuç vermemektedir [11]. Bulanık mantık kurallarının kullanıldığı yöntem ile gürültünün kenar bulma üzerindeki olumsuz etkisi en aza indirilmeye çalışılmıştır [2].

\subsection{Bulanık Mantık}

Bulanık mantık konusunda Lütfi Aliasker Zade'nin 1961 yılında yayınlanan makalesinde bir varlığın bir kümeye aitliğinin $(0,1)$ arasında değer alabileceği ilk olarak ifade edilmiştir [12]. Bir görüntüde bir pikselin kenar pikseli olma oranı bulanık mantıkla ifade edilebilmektedir [11]. Bu oran üyelik değeri ile belirlenmekte olup üyelik değerini hesaplayan bir üyelik fonksiyonu mevcuttur. Üyelik değerleri belirlendikten sonra bu değerlere bağlı olarak bulanık kurallar hesaplanır. Bulanık kuralların üyelik değerleri daha sonra ağırlıklı ortalama yöntemine göre durulaştırılır.

\subsection{Bulanık Mantık Tabanlı Kenar Çıkarma}

Bir pikselin komşu pikseliyle gri seviye farkı $x_{k} ; k \in\{1,2, \ldots \ldots 8\}$ 'dir. Merkez(Q) pikseli ve "?" işareti ile gösterilen pikseller kenar çizgisi kabul edilirse sekiz farklı yönde kenar durumu oluşmaktadır. Bu kenar durumlarının oluşturduğu Bulanık Kural şablonları Şekil 1'de gösterilmektedir [13].

B1

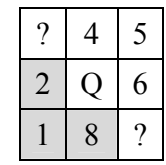

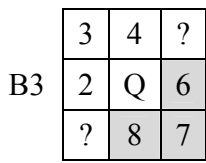

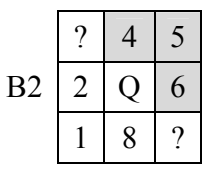

B4

\begin{tabular}{|c|c|c|}
\hline 3 & 4 & $?$ \\
\hline 2 & Q & 6 \\
\hline$?$ & 8 & 7 \\
\hline
\end{tabular}

\begin{tabular}{|l|l|l|}
\hline 3 & 4 & 5 \\
\hline$?$ & $\mathrm{Q}$ & $?$ \\
\hline 1 & 8 & 7 \\
\hline
\end{tabular}

B7

\begin{tabular}{|c|c|c|}
\hline 3 & $?$ & 5 \\
\hline 2 & $\mathrm{Q}$ & 6 \\
\hline 1 & $?$ & 7 \\
\hline
\end{tabular}

B6

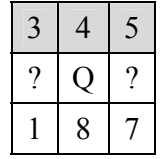

B8

\begin{tabular}{|c|c|c|}
\hline 3 & $?$ & 5 \\
\hline 2 & Q & 6 \\
\hline 1 & $?$ & 7 \\
\hline
\end{tabular}

Şekil 1. Bulanık Kural Şablonları

Gri seviye farkı $x$ 'e bağlı üyelik fonksiyonları $A c ̧ \iota k(x)$ ve $K o y u(x)$, denklem 1 ve 2'de tanımlanmıştır [2].

$$
A c ̧ \iota k(x)=\left\{\begin{array}{lr}
0, & x \leq 0 \\
\frac{x}{c}, & 0<x<c \\
1, & x \geq c
\end{array}\right.
$$




$$
\operatorname{Koyu}(x)=\left\{\begin{array}{rr}
0, & x \leq-c \\
-\frac{\mathrm{x}}{\mathrm{c}}, & -c<x<0 \\
1, & x \geq 0
\end{array}\right.
$$

\subsection{Maksimum Entropi Belirleme}

BK üyelik değerleri Bulanık Kural Şablonlarına göre hesaplanmaktadır. Açık ve Koyu üyelik değerlerinin hesaplanması için c değerinin bilinmesi gerekir. Yöntemin ilk aşamasında adaptif olarak optimum c değeri belirlenir. Sonraki aşamada optimum c değerine göre Açık ve Koyu üyelikler tekrar hesaplanarak BK'nin üyelik değerleri ortaya çıkarılır. Bir görüntüdeki tüm piksellerin denklem 1 ve 2'ye göre Açık ve Koyu üyelik değerlerinin hesaplanması gerekir. Boyutları $\mathrm{MxN}$ olan bir görüntüde bütün pikseller için $x_{k}$ hesaplanır. $\mu=\left\{\mu_{i j k}, \mathrm{n}=\mathrm{i} * \mathrm{j} * \mathrm{k} \mid \mathrm{i}=1, \ldots \mathrm{M}, \mathrm{j}=1, \ldots \mathrm{N}, \mathrm{k}=1, \ldots 8\right\}$ üyelik değeri denklem 3'de verilmiştir [2]. Bir piksel için Açık ve Koyu üyelik değerlerinden sadece biri pozitif değer almakta diğeri ise sıfır olmaktadır. Açık ve Koyu üyelik değerleri toplanarak $\mu_{i j k}$ üyelik değeri elde edilir.

$\mu_{i j k}=\operatorname{Açlk}\left(x_{k}\right)+\operatorname{Koyu}\left(x_{k}\right)$

Shannon Entropi ifadesine göre bir olayın olasılıklarının oluşturduğu kümenin entropisi $H=-\sum p_{i} \log p_{i}$ ile gösterilmektedir [14]. Yöntemde Shannon Entropi ifadesi ile elde edilen tüm $\mu_{i j k}$ üyelik değerlerinin ortalaması hesaplanmaktadır. Denklem 4'de Entropiyi hesaplamak için kullanılan Shannon fonksiyonu belirtilmektedir [2].

$S_{n}\left(\mu_{i j k}\right)=-\mu_{i j k} \log _{2} \mu_{i j k}-\left(1-\mu_{i j k}\right) \log _{2}\left(1-\mu_{i j k}\right)$

Bir görüntü için Shannon fonksiyonu ile hesaplanan $n$ adet üyelik değeri kabul edilmektedir. Bu üyeliklerin ortalaması alınarak ortalama entropi değeri bulunmaktadır. Her $c=1, \ldots 255$ değeri için farklı bir ortalama entropi değeri hesaplanmaktadır. Sonraki aşamada bu değerler $H(O, c)$ dizisine atanmaktadır. Ortalama entropi değerleri denklem 5 'de gösterilmektedir [2].

$H(O, c)=\frac{1}{8 \times M \times N} \sum_{k=1}^{8} \sum_{i=1}^{M} \sum_{j=1}^{N}\left(S_{n}\left(\mu_{i j k}\right)\right)$ 


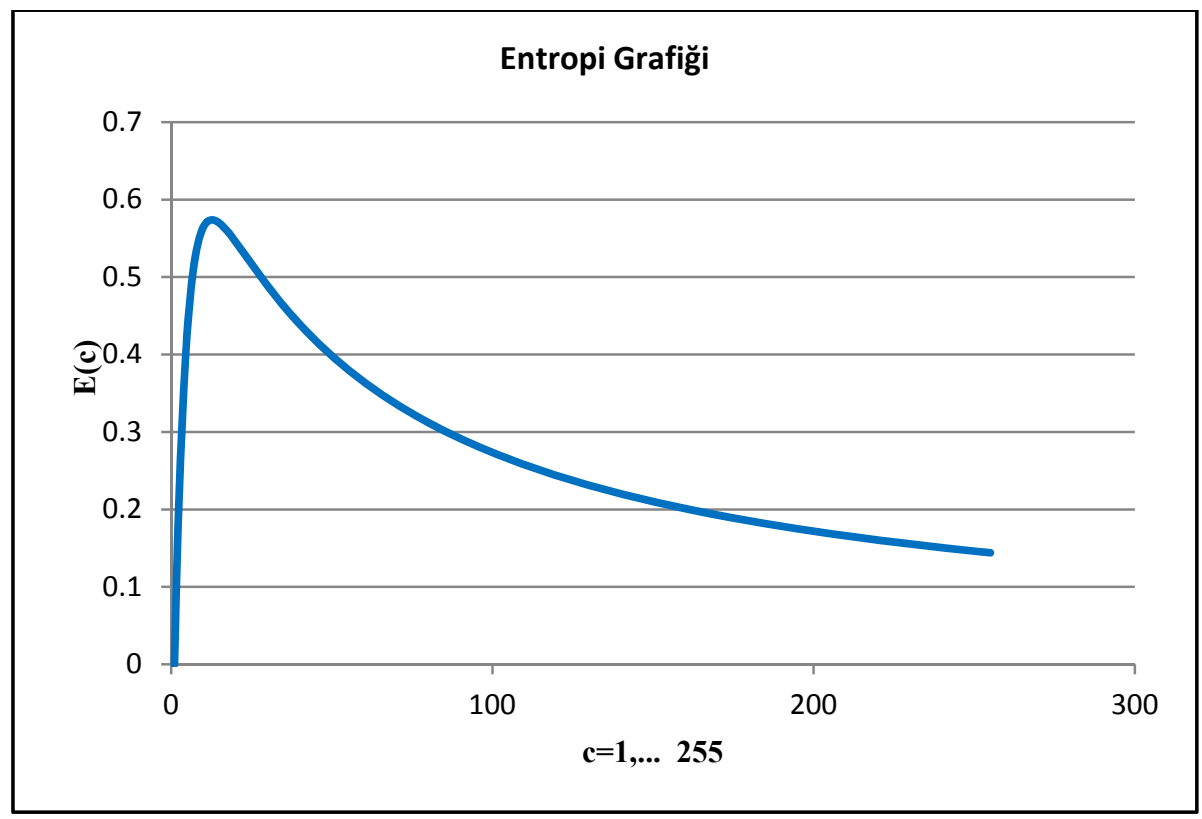

Şekil 2. \%0.2 Tuz ve biber gürültüsü eklenmiş Lena görüntüsünün $c^{6}$ ye bağlı entropi değiş̧imi

Şekil 2'de c değerlerinin verilen aralıktaki değişimine karş1 hesaplanan ortalama entropi değerleri gösterilmektedir. Maksimum entropinin üretildiği noktadaki c değeri optimum c olarak belirlenir.

\section{4. Önerilen Birinci Geliştirme}

Tuz ve Biber gürültüsü $\% 20$ veya üzeri oranda eklenmiş görüntülerde entropi değişimi Şekil 2'deki gibi tek bir tepe noktası oluşturmamaktadır. Çoğunlukla birden fazla tepe noktasi oluşturmaktadır. $\mathrm{Bu}$ durumda ortalama entropi değeri maksimum olan seçilememektedir. Çünkü ilk tepe noktasından sonra oluşan tepe değerler yüksek seviyeli gürültü etkisinden kaynaklanmaktadır. Farklı görüntülere ait entropi değişimleri Şekil 3'de gösterilmektedir.

Optimum c için E(c)'nin maksimum olarak alınması [2]'de anlatılan yöntemde yüksek gürültü seviyeleri için hatalı sonuç vermektedir. Bu durumda optimum c değeri, ilk tepe noktasındaki c değeri seçilmelidir. Yapılan denemelerde Tuz ve Biber gürültüsü \%20'ye yakın veya daha düşük olan görüntüler için çoğunlukla tek bir tepe değer olduğu tespit edilmiştir. Şekil 2'de görüldüğü gibi belirli bir c değeri için ortalama entropi maksimum olmaktadır. Maksimum entropinin hangi c değerinde ortaya çıkacağı bilinmediğinden, c değerlerinin tamamında adaptif olarak ortalama entropinin hesaplanması gerekmektedir. Ortalama entropinin hesaplanması oldukça zaman alan bir işlem olduğundan bu şekilde sonuca ulaşılması verimsizdir. 
a

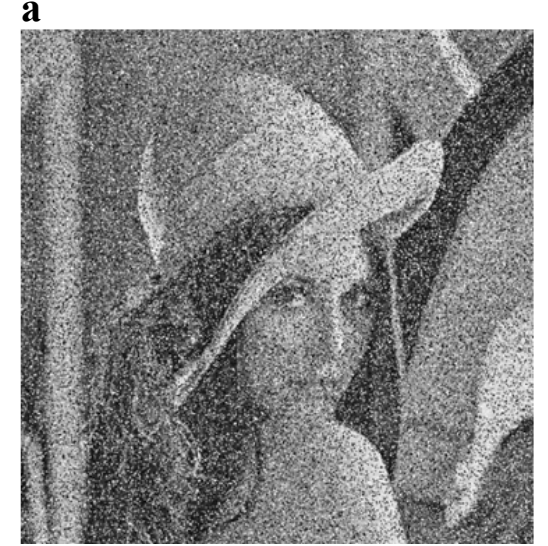

c

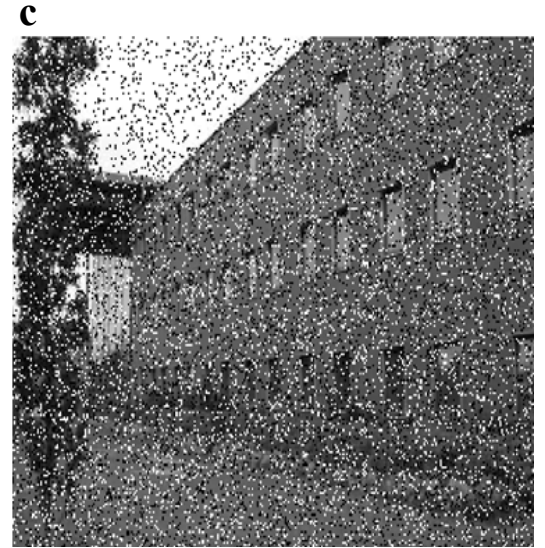

e

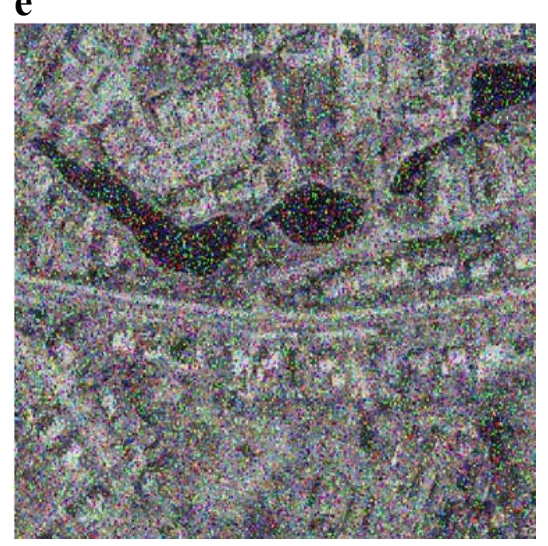

b

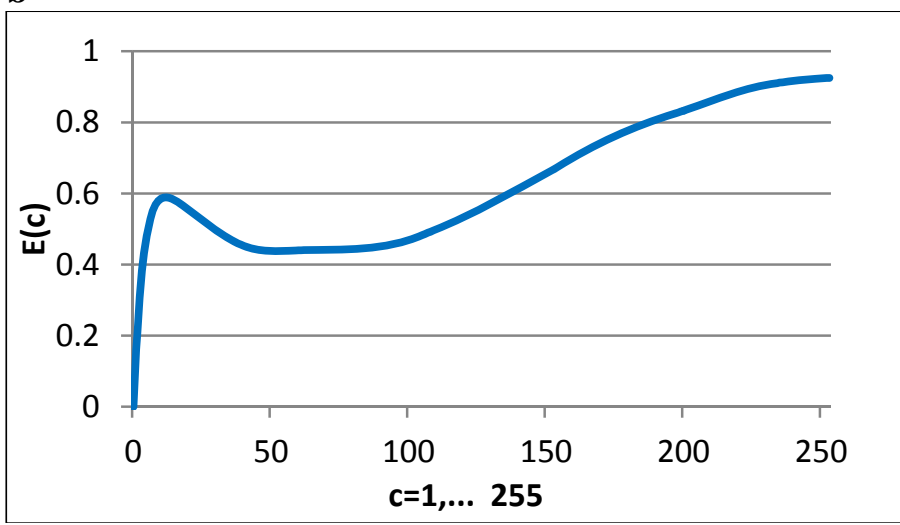

d

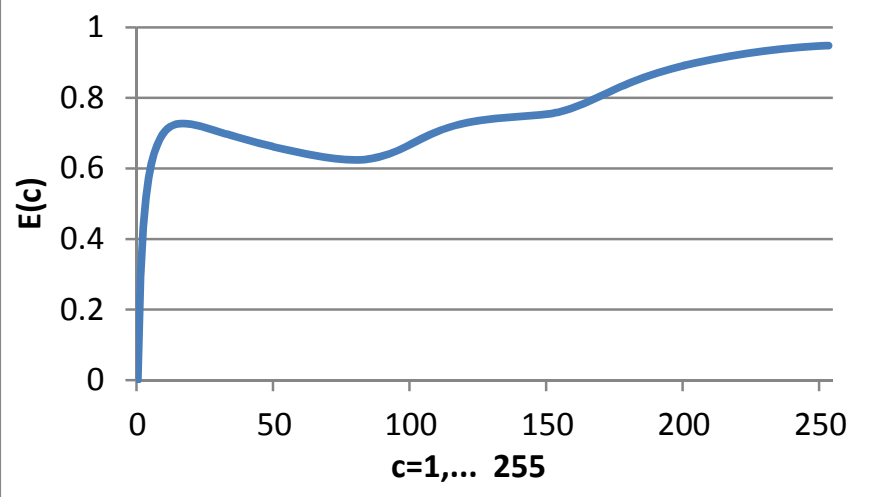

f

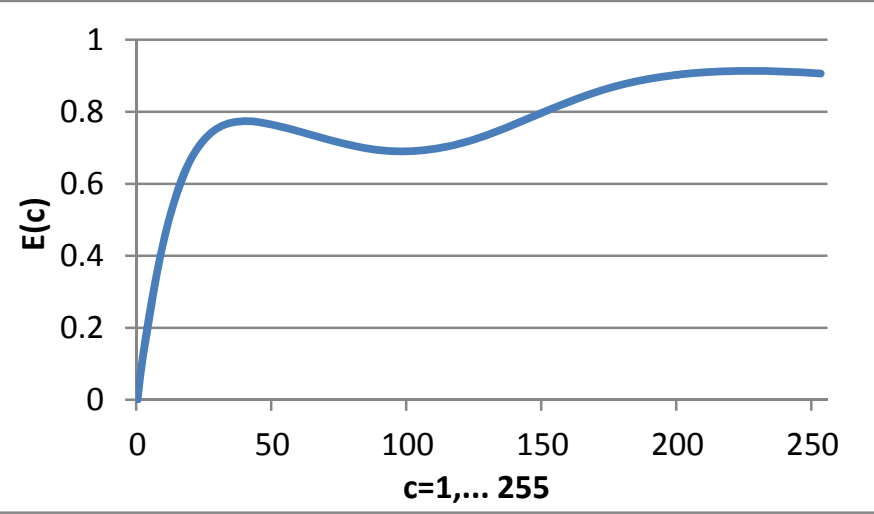

Şekil 3. (a) \%30 Tuz ve biber gürültüsü eklenmiş Lena görüntüsü, (b) Lena görüntüsüne ait entropi grafiği, (c) \%20 Tuz ve biber gürültüsü eklenmiş gri bina görüntüsü, (d) Gri bina görüntüsüne ait entropi grafiği, (e) \%20 Tuz ve biber gürültüsü eklenmiş uydu görüntüsü, (f) Uydu görüntüsüne ait entropi grafiği

Maksimum E(c)'yi bulan maksimum entropi belirleme yöntemi (MEBY) burada anlatılmaktadır. MEBY'nin amacı tepe noktasının hızlı bir şekilde tespit edilmesidir. MEBY ile $\mathrm{c}=1, \ldots 255$ aralığ 16 parçaya bölünmektedir. Burada 16 değeri $\mathrm{p}^{*} \mathrm{q}=256$ denkleminden bulunmaktadır. Minimum sayıda c değerinin hesaplamaya dâhil edilmesi için $\mathrm{p}$ ve q değerleri en az 16 seçilebilmektedir. İlk olarak c değeri her adımda 16 artırılarak E(c) değerlerine bakılmaktadır. Maksimum E(c) bu aralıklardan birine denk gelmektedir. Maksimum E(c) değerinden sonra E(c) azalmakta ve azalmanın olduğu bu aralığın tepe noktasının bulunduğu aralık olduğu anlaşılmaktadır. Bu aralıkta c değerine, c_ilk değerinin 16 eksiği atanmaktadır. Daha sonra adımlar birer artırılarak 
kontrol yapılmaktadır. E(c)'nin azaldığı yerde program sonlandırılmakta, maksimum E(c) ve c değeri tespit edilmektedir. MEBY'nin akış diyagramı Şekil 4'de gösterilmektedir.

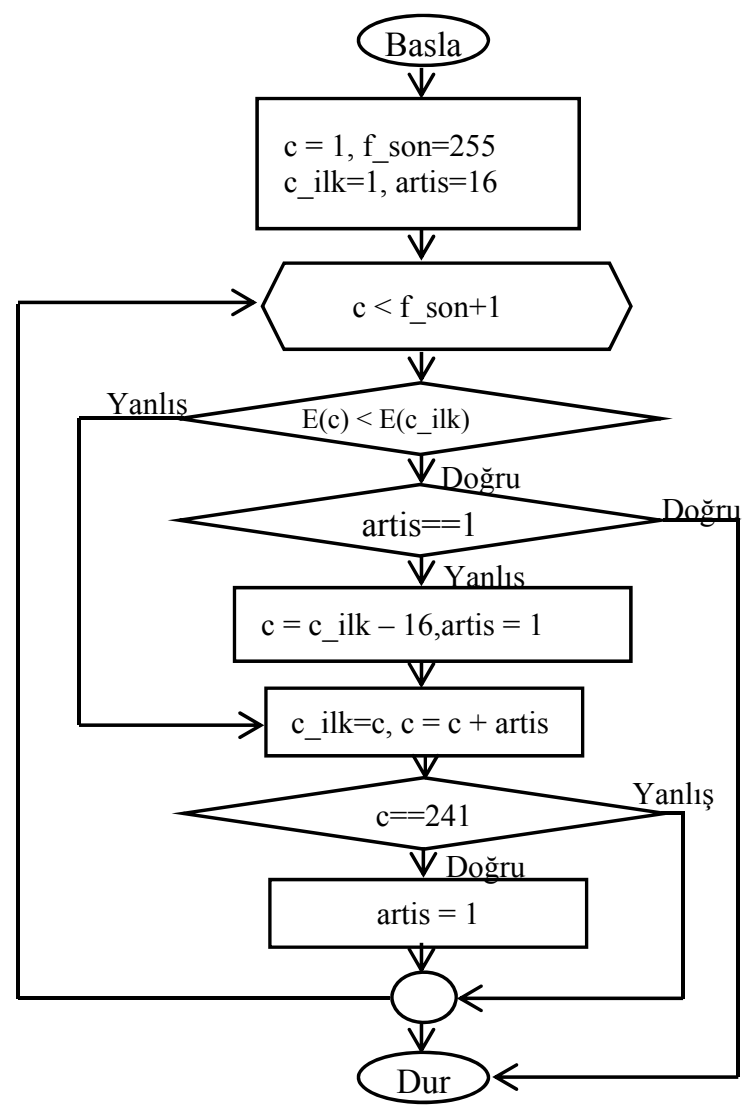

Şekil 4. Maksimum c değerinin bulunması

\subsection{BK'nin ve KDK'nin Tespiti}

Adaptif olarak c değerinin tespit edilmesinden sonra Açık ve Koyu üyelikler optimum c'ye göre hesaplanmaktadır. Merkez(Q) pikselin Şekil 1'de belirlenen komşuları için $A c ̧ \iota k(x)$ ve $K o y u(x)$ üyelik fonksiyonları için üyelik değerleri hesaplanmaktadır.

Koyu renkli komşular için $\operatorname{Koyu}(x)$, açık renkli olanlar için $A c ̧ \iota k(x)$ üyelikler değerlendirmeye alınmaktadır. Şekil 1'e göre bulanık kurallar sekiz farklı şekilde tespit edilmektedir. BK1 Şekil 1'deki B1 için hesaplanmaktadır. "?" işareti ile gösterilen komşu pikseller $\operatorname{Aç} 1 \mathrm{k}(\mathrm{x})$ ve $\operatorname{Koyu}(\mathrm{x})$ üyelik değerlerinin hesaplanmasına dâhil edilmemektedir. " $\cap$ " operatörü ağırlıklı aritmetik ortalamayı, " $\cap_{v e}$ " operatörü minimumu ve " $U$ " operatörü maksimumu temsil etmektedir [2]. BK1 denklem 6' da ifade edilmektedir. BK2...BK8 kuralları Şekil 1'deki B2...B8 şablonlarına göre belirlenmektedir.

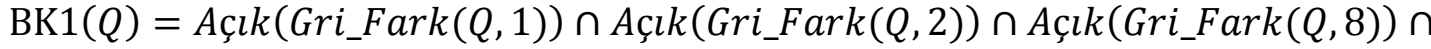
$\operatorname{Koyu}(\operatorname{Gri} F a r k(Q, 4)) \cap \operatorname{Koyu}(\operatorname{Gri} F a r k(Q, 5)) \cap \operatorname{Koyu}(\operatorname{Gri} F a r k(Q, 6))$

BK üyeliklerin belirlenmesinden sonra BK1...BK8 üyelik değerleri kullanılarak durulaştırma yapılabilmektedir. Eğer ihtiyaç olursa daha sonra KDK kullanılarak bulunacak üyelik değerleri ile durulaştırma yapılabilmektedir. Kenar devamlılığı ile 
kenar bulma yönteminde asıl amaç Tuz ve Biber gürültüsü içeren görüntülerde kenarların bulunmasıdır. KDK üyelik değerleri Şekil 1'de “?” işareti ile gösterilen piksellerin komşuları ile belirlenmektedir. $\mathrm{Bu}$ komşuların $\mathrm{BK}$ üyelik değerleri hesaplamaya katılmaktadır. "?" ile gösterilen pikselin BK1...BK8 üyelik değerleri bulunmakta ve arasından en büyük olanı seçilmektedir. KDK1 için [2]'de bahsedilen şablonlar Şekil 5'de gösterilmektedir.

B1

\begin{tabular}{|c|c|c|}
\hline$?$ & 34 & 35 \\
\hline 32 & 3 & 36 \\
\hline 31 & 38 & $?$ \\
\hline
\end{tabular}

B1

\begin{tabular}{|c|c|c|}
\hline$?$ & 4 & 5 \\
\hline 2 & $\mathrm{Q}$ & 6 \\
\hline 1 & 8 & $?$ \\
\hline
\end{tabular}

B1

\begin{tabular}{|c|c|c|}
\hline$?$ & 74 & 75 \\
\hline 72 & 7 & 76 \\
\hline 71 & 78 & $?$ \\
\hline
\end{tabular}

B5

\begin{tabular}{|c|c|c|}
\hline 33 & 34 & 35 \\
\hline$?$ & 3 & $?$ \\
\hline 31 & 38 & 37 \\
\hline
\end{tabular}

\begin{tabular}{|l|l|l|}
\hline 33 & $?$ & 35 \\
\hline 32 & 3 & 36 \\
\hline 31 & $?$ & 37 \\
\hline
\end{tabular}

\begin{tabular}{|c|c|c|}
\hline 73 & $?$ & 75 \\
\hline 72 & 7 & 76 \\
\hline 71 & $?$ & 77 \\
\hline
\end{tabular}

Şekil 5. Q pikselinin 3 ve 7 numaralı komşuları için KDK1 şablonu

KDK1'in hesaplanması için Q pikselinin “?” işareti ile gösterilen 3 ve 7 numaralı komşu piksellerinin B1,B5 ve B7 üyelik değerleri bilinmelidir. İlk aşamada tüm pikseller için hesaplanan BK değerlerinden faydalanılarak B1, B5 ve B7 değerleri ile KDK1'in hesaplanması denklem 7'de gösterilmektedir. KDK2..KDK8 için üyelik fonksiyonları [2]'de anlatılmaktadır.

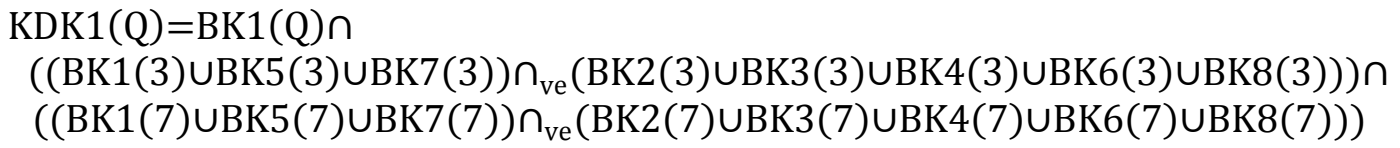

\section{6. Önerilen İkinci Geliştirme}

BK üyelik değerleri ve ardından BK'ye dayalı KDK üyelik değerleri tespit edilir [2]. Burada önerilen ikinci geliştirme ile Tuz ve Biber gürülttüsü az olan görüntülerde KDK üyelik değeri hesaplamaya dâhil edilmemektedir. Böylece işlem yükü azaltılmaktadır. KDK'nin amacı Tuz ve Biber gürültüsü içeren görüntülerde kenarların bulunmasıdır. Dolayısıyla gürültüsü az görüntülerde KDK'ye ihtiyaç duyulmamaktadır.

Görüntünün, gürültü miktarına göre farklı işleme tabi tutulması gerekmektedir. Burada iki farklı yol vardır. İlk yol gürültü seviyesi fazla görüntüler için BK üyeliklerinin ve KDK üyeliklerinin bulunmasıdır. Diğer yol ise gürültü seviyesi az görüntüler için sadece BK üyeliklerinin bulunmasıdır. Burada önerilen ikinci geliştirmeyle bu iki yol arasında seçim işlemi yapılmaktadır. Seçim işlemi ile sadece BK üyeliklerin hesaplanması KDK'ye ihtiyacı ortadan kaldırmaktadır. Bu seçim için görüntüdeki gürültü oranı hakkında bilgi sahibi olmamız gerekmektedir.

Sinyal Gürültü Oranı(SGO) görüntüdeki gürültü oranı hakkında bilgi vermektedir. Tuz ve biber gürültüsü arttıkça SGO azalmaktadır [6]. MxN boyutlu bir görüntüdeki SGO oranı denklem 8 'de belirtilmiştir. Bu ifadede $f$ filtrelenmiş görüntü, $k$ orijinal görüntü olmaktadir. 
$S G O=10 \log _{10} \frac{\left(\frac{1}{M N}\right) \sum_{m=1}^{M} \sum_{n=1}^{N} f(i, j)^{2}}{\left(\frac{1}{M N}\right) \sum_{m=1}^{M} \sum_{n=1}^{N}[f(i, j)-k(i, j)]^{2}}$

Görüntülerdeki tuz ve biber oranı farklı düzeylerde olabilmektedir. SGO'nun bulunması için $k$ orijinal görüntüsü ile $f$ filtrelenmiş görüntüsü denklem 8 'deki gibi işleme sokulmaktadır. Burada filtrelenmiş $f$ görüntüsü orijinal $k$ görüntüsünün filtreden geçirilmiş halidir. Bu filtreleme işlemi için Median filltre kullanılmaktadır.

Median filtre gürültü azaltmada bilinen etkili bir yöntemdir [7]. Median filtrede bir pencereyi oluşturan piksellerin değerleri büyükten küçüğe sıralanmaktadır. Sıralanmış değerlerin ortasında yer alan değer merkez değer kabul edilmekte ve pencerenin ortasına yerleştirilmektedir. $\{\mathrm{x}, \mathrm{y}\}$ boyutlu bir görüntüde $\{\mathrm{s}, \mathrm{t}\}$ boyutlu bir pencerenin median ifadesi denklem 9'da gösterilmektedir [15].

$f(x, y)=\operatorname{median}_{(s, t) \in S_{x y}}\{g(s, t)\}$

Önerilen ikinci geliştirmede görüntünün filtreden geçirilmiş hâli(f) ile orijinal hâli(k) denklem 8'de ilgili yerlere yerleştirilerek SGO değeri elde edilmektedir. Orijinal görüntü tuz ve biber gürültüsü içeriyorsa median filtre ile gürültüsü azaltılmaktadır. Eğer orijinal görüntü tuz ve biber gürültüsü içermiyorsa median filtreleme işlemi orijinal görüntü üzerinde gürültü azaltma yapamamaktadır. Böylece filtrelenmiş görüntü ile orijinal görüntü arasında fazla fark oluşmamaktadır.

Tuz ve Biber gürültüsü ihtiva eden görüntülerde filtreleme sonucunda oluşan fark SGO değeriyle tespit edilebilmektedir. Gürültünün fazla olduğu görüntülerde SGO değeri 0’a yaklaşmakta, tersi durumda ise 100'e yaklaşmaktadır. Görüntülere $\% 1$ oranında Tuz ve Biber eklemenin SGO değerini yaklaşık 20 yaptığı tespit edilmektedir. Bu sonuca denemelerle ulaşılmaktadır. Tuz ve Biber oranının $\% 1$ veya altıda olduğu görüntülerde KDK ile durulaştırma işlemine çok fazla ihtiyaç duyulmamaktadır. Burada önerilen ikinci geliştirme ile SGO değerine göre seçim yapılmaktadır. SGO değeri 20'nin üzerinde olan görüntülere sadece BK üyelikleriyle durulaştırma, SGO değeri 20'nin altında olan görüntülere BK kullanılarak hesaplanan KDK üyelikleriyle durulaştırma uygulanmaktadir.

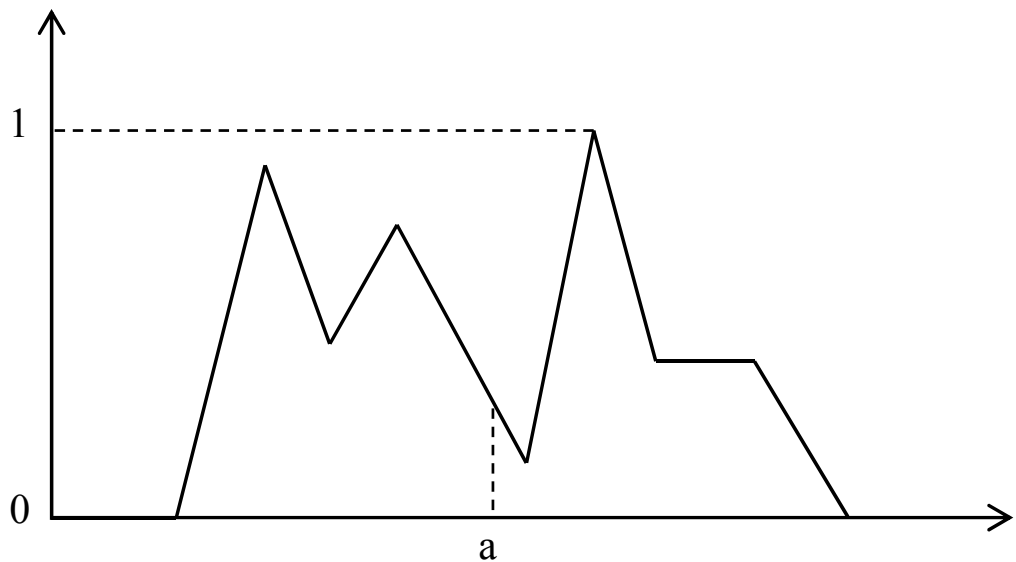

Şekil 6. Ağırlık merkezi yöntemi grafiği(a:ağırlık merkezi) 
Durulaştırma son aşamada yapılmaktadır. Bulanık kuralların durulaştırılabilmesi için farklı durulaştırma yöntemleri mevcuttur [16]. Bunlara en büyük üyelik yöntemi, ağırlık merkezi yöntemi, ağırlıklı ortalama yöntemi ve ortalama en büyük üyelik yöntemi örnek olarak verilebilir. Ağırlık merkezi yöntemi grafiksel olarak Şekil 6'da gösterilmektedir.

BK ve KDK'de durulaştırma için ağırlık merkezi yöntemi kullanılmaktadır. Ağırlık merkezi yöntemi denklem 10 'da ifade edilmektedir [17]. $\mu(z)$ üyelik fonksiyonunu ifade etmektedir.

$z^{*}=\frac{\int \mu(z) z d z}{\int \mu(z) d z}$

Programda ilk olarak SGO değeri ve BK üyelik değerleri bulunmaktadır. SGO değerine göre durulaştırmaya BK veya KDK değerleri dâhil edilir. Programın akış diyagramı Şekil 7'de verilmektedir.

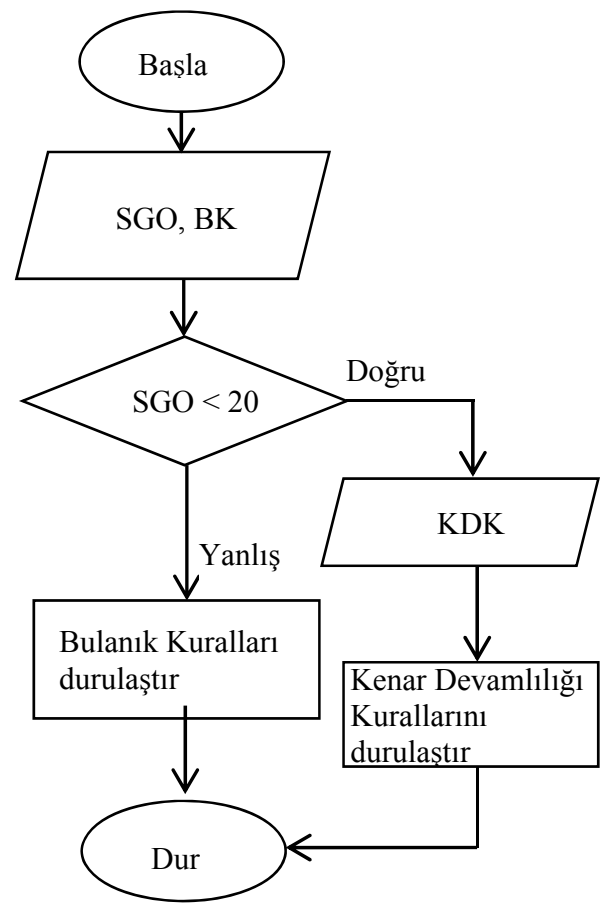

Şekil 7. Kenar belirleme programının akış diyagramı

\section{Deneysel Sonuçlar}

Şekil 8,9,10 ve 11 'de Canny, Roberts, Sobel, BK ve KDK sonuçları gösterilmektedir. Matlab'da Lena görüntüsü denenmiştir. Tuz ve biber oran1, SGO değeri, Canny, Roberts ve Sobel için kullanılan eşik değerleri şekil açıklamalarında belirtilmektedir. 
$\mathbf{a}$

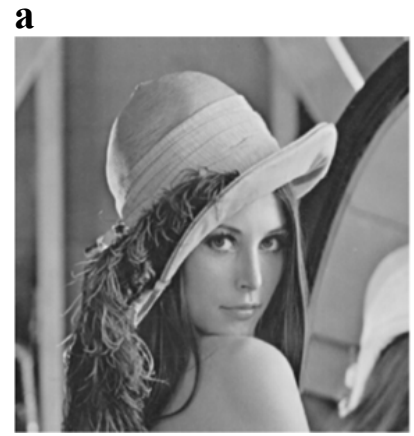

d

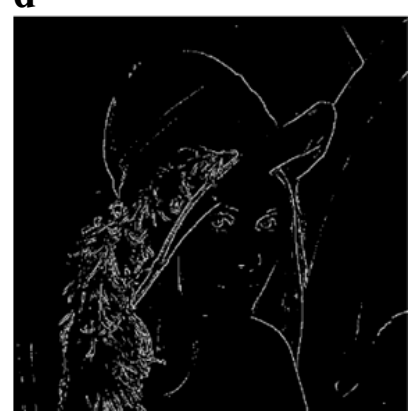

b

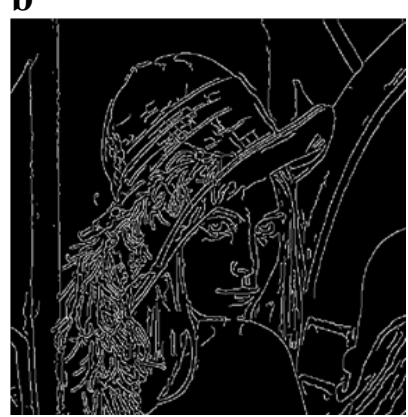

e

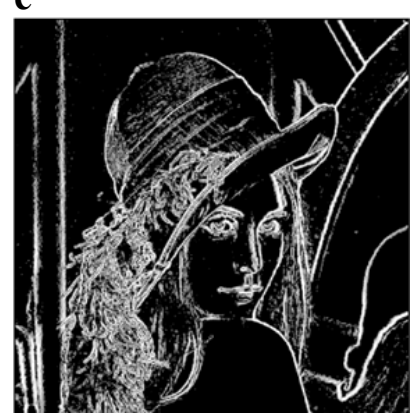

c
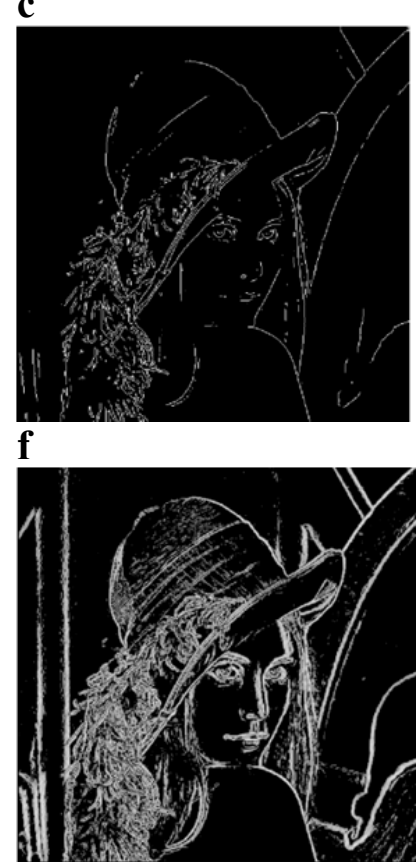

Şekil 8. (a) Orijinal Lena görüntüsü(SGO:29.7), (b) Canny(0.09), (c) Sobel(0.08), (d) Roberts(0.08), (e) BK, (f) KDK

a

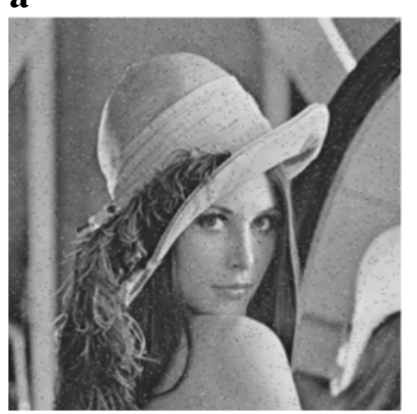

d

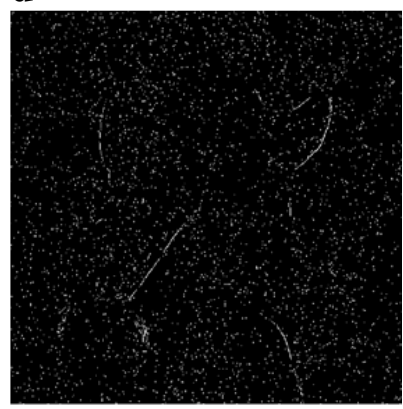

b

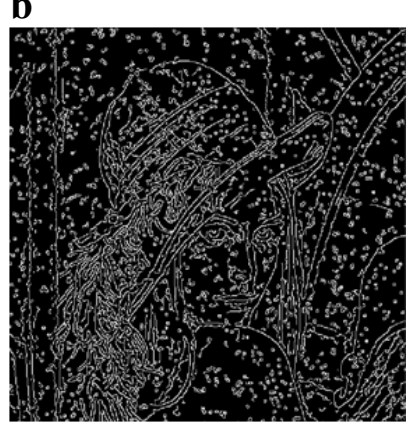

e

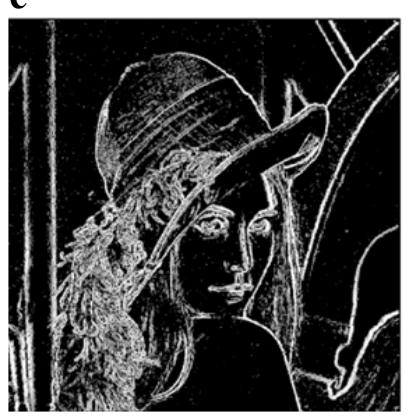

c

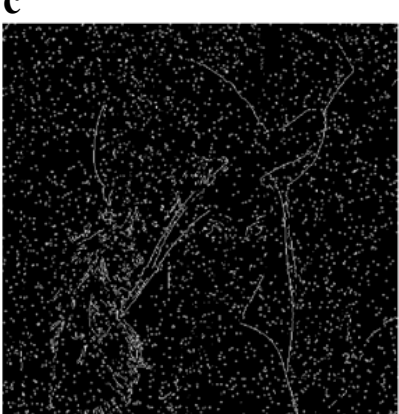

f

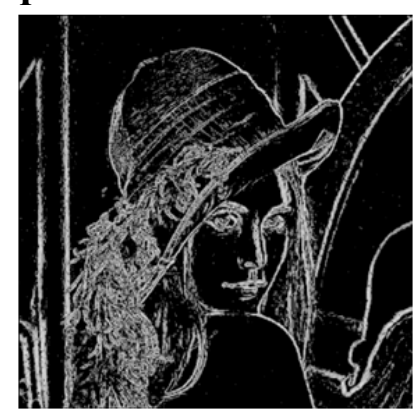

Şekil 9. (a) \%2 Tuz ve biber gürültüsü eklenmiş Lena görüntüsü(SGO: 16.7),

(b) Canny(0.12), (c) Sobel(0.12), (d) Roberts(0.20), (e) BK, (f) KDK 
$\mathbf{a}$

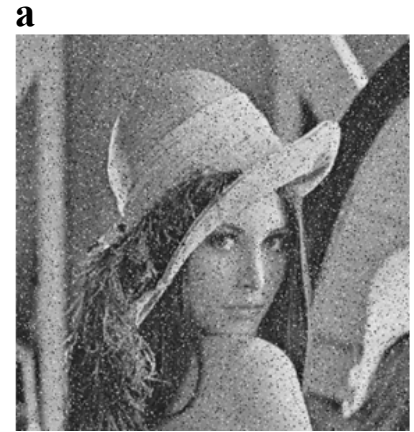

d

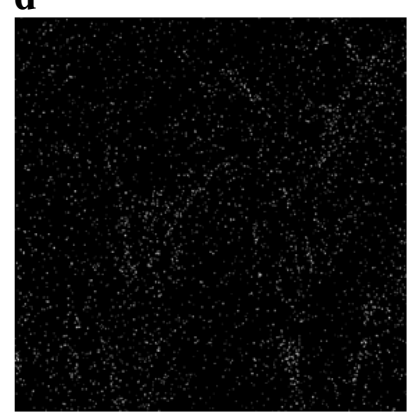

b

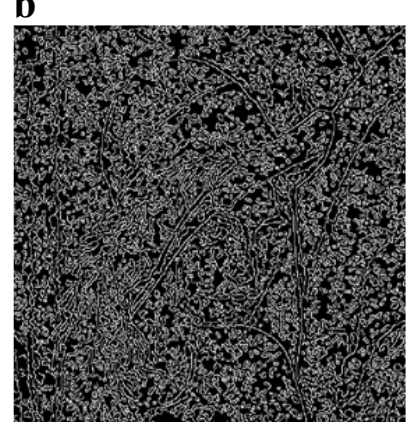

e

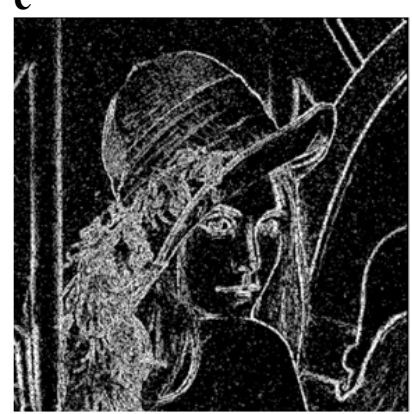

c
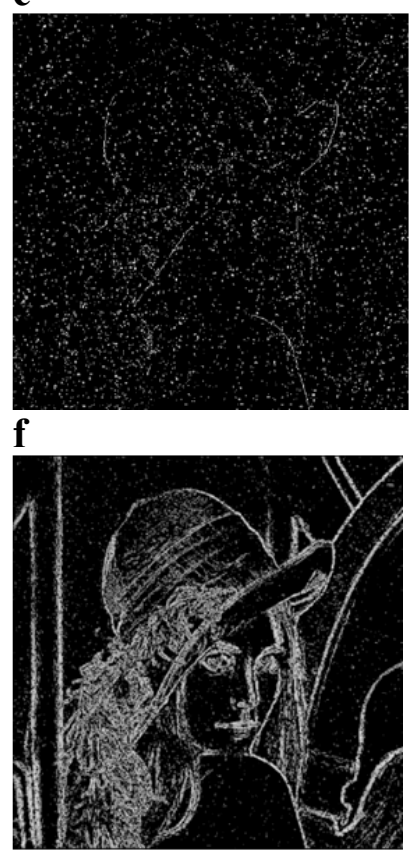

Şekil 10. (a) \%10 Tuz ve biber gürültüsü eklenmiş Lena görüntüsü(SGO: 9.7), (b) Canny(0.17), (c) Sobel(0.21), (d) Roberts(0.41), (e) BK, (f) KDK

$\mathbf{a}$

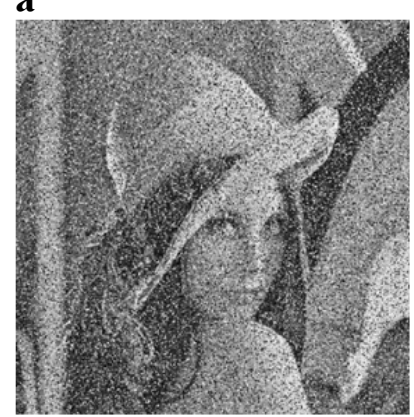

d

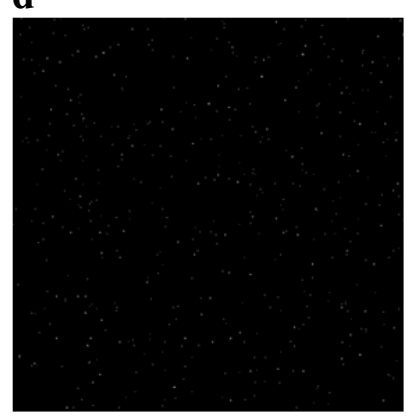

b

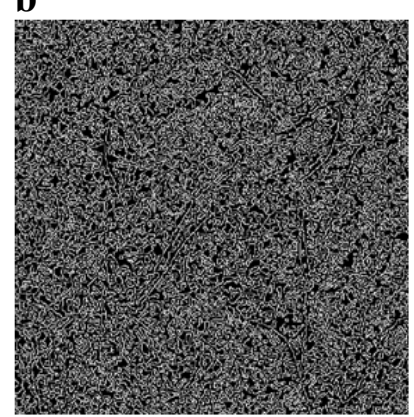

e

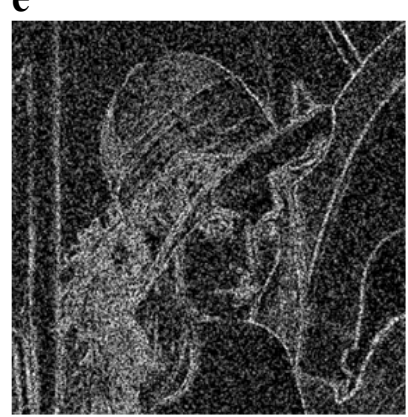

c

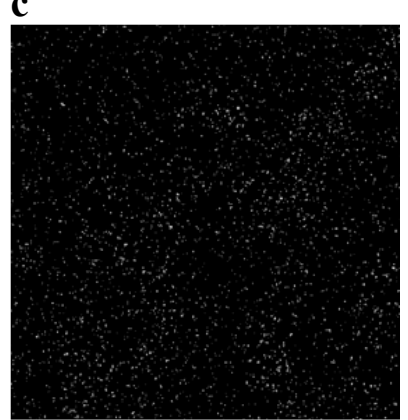

f

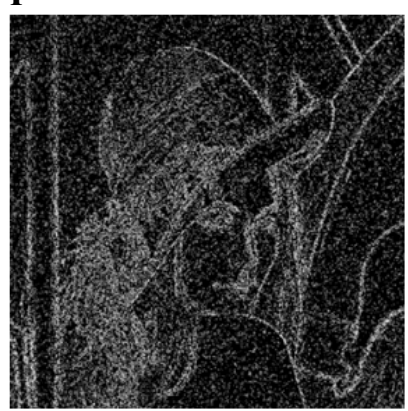

Şekil 11. (a) \%30 Tuz ve biber gürültüsü eklenmiş Lena görüntüsü(SGO: 5.1), (b) Canny(0.25), (c) Sobel(0.35), (d) Roberts(0.70), (e) BK, (f) KDK

\subsection{Yöntemlerin Karşılaştırılması}

BK, KDK, Canny, Sobel ve Roberts yöntemlerinin kullanımıla elde edilen deneysel sonuçlar karşılaştırılmaktadır. Karşılaştırma sonuçları Tablo 1'de gösterilmektedir. 
Tablo 1. Gürültünün bozucu etkisi, parametre kullanımı ve detayların kaybolması durumlarının yöntemler arasında karşılaştırılması

\begin{tabular}{|c|c|c|c|c|c|c|}
\hline \multirow{2}{*}{ Görüntü } & \multirow{2}{*}{$\begin{array}{c}\text { Karşılaştırılan } \\
\text { Durumlar }\end{array}$} & \multicolumn{5}{|c|}{ Yöntemler } \\
\hline & & $\mathrm{BK}$ & KDK & Canny & Sobel & Roberts \\
\hline \multirow{3}{*}{$\begin{array}{c}\text { Orijinal } \\
\text { 512x512 Lena } \\
\text { Görüntüsü }\end{array}$} & Parametre değeri & Yok & Yok & 0.09 & 0.08 & 0.08 \\
\hline & $\begin{array}{c}\text { Gürültünün bozucu } \\
\text { etkisi }\end{array}$ & Yok & Yok & Yok & Yok & Yok \\
\hline & $\begin{array}{c}\text { Detayların } \\
\text { kaybolmas1 }\end{array}$ & Yok & Yok & Yok & Var & Var \\
\hline \multirow{3}{*}{$\begin{array}{c}\% 2 \text { Tuz ve } \\
\text { biber gürültüsü } \\
\text { eklenmiş } \\
\text { 512x512 Lena } \\
\text { Görüntüsü }\end{array}$} & Parametre değeri & Yok & Yok & 0.12 & 0.12 & 0.20 \\
\hline & $\begin{array}{c}\text { Gürültünün bozucu } \\
\text { etkisi }\end{array}$ & Yok & Yok & Var & Var & Var \\
\hline & $\begin{array}{c}\text { Detayların } \\
\text { kaybolmas1 }\end{array}$ & Yok & Yok & Var & Var & Var \\
\hline \multirow{3}{*}{$\begin{array}{l}\text { \%10 Tuz ve } \\
\text { biber gürültüsü } \\
\text { eklenmiş } \\
512 \times 512 \text { Lena } \\
\text { Görüntüsü } \\
\end{array}$} & Parametre değeri & Yok & Yok & 0.17 & 0.21 & 0.41 \\
\hline & $\begin{array}{c}\text { Gürülttünün bozucu } \\
\text { etkisi }\end{array}$ & Yok & Yok & Var & Var & Var \\
\hline & $\begin{array}{c}\text { Detayların } \\
\text { kaybolmas1 }\end{array}$ & Yok & Yok & Var & Var & Var \\
\hline \multirow{3}{*}{$\begin{array}{l}\% 30 \text { Tuz ve } \\
\text { biber gürültüsü } \\
\text { eklenmiş } \\
\text { 512x512 Lena } \\
\text { Görüntüsü }\end{array}$} & Parametre değeri & Yok & Yok & 0.25 & 0.35 & 0.70 \\
\hline & $\begin{array}{c}\text { Gürültünün bozucu } \\
\text { etkisi }\end{array}$ & Var & Var & Var & Var & Var \\
\hline & $\begin{array}{l}\text { Detayların } \\
\text { kaybolmas } 1\end{array}$ & Var & Var & Var & Var & Var \\
\hline
\end{tabular}

\subsection{Hesaplama Maliyeti Analizi}

Program Core i5-2430M $2.4 \mathrm{GHz}$ işlemcili bir bilgisayarda Matlab R2015a ile çalıştırılmıştır. Ticari yazılımlar açısından programın çalışma süresi önem arz etmektedir. MEBY'nin ve SGO'nun kenar bulmaya dâhil edilip edilmemesi, her iki durumda ölçülen programın çalışma süreleri ve yüzde süre kazançları Tablo 2'de gösterilmektedir.

Tablo 2. Programın çalışma süreleri

\begin{tabular}{|c|c|c|c|c|c|}
\hline Görüntü & $\begin{array}{l}\text { SGO } \\
\text { Değeri }\end{array}$ & $\begin{array}{l}\text { MEBY'nin } \\
\text { kullanılmas1 }\end{array}$ & $\begin{array}{l}\text { SGO ile } \\
\text { seçim } \\
\text { yapma }\end{array}$ & $\begin{array}{l}\text { Programın } \\
\text { çalışma } \\
\text { süresi }\end{array}$ & $\begin{array}{c}\text { Çalışma } \\
\text { süresindeki } \\
\text { azalma (\% olarak) }\end{array}$ \\
\hline \multirow{3}{*}{$\begin{array}{c}\text { Orijinal } 512 \times 512 \text { Lena } \\
\text { Görüntüsü }\end{array}$} & \multirow{3}{*}{29.7} & Dâhil & Dâhil & $12.9 \mathrm{~s}$ & $\% 89$ \\
\hline & & Dâhil & Dâhil değil & $19.5 \mathrm{~s}$ & $\% 83$ \\
\hline & & Dâhil değil & Dâhil değil & $120.2 \mathrm{~s}$ & 0 \\
\hline \multirow{3}{*}{$\begin{array}{l}\text { \%2 Tuz ve biber gürültüsü } \\
\text { eklenmiş } 512 \times 512 \text { Lena } \\
\text { Görüntüsü }\end{array}$} & \multirow{3}{*}{16.7} & Dâhil & Dâhil & $19.4 \mathrm{~s}$ & $\% 83$ \\
\hline & & Dâhil & Dâhil değil & $19.4 \mathrm{~s}$ & $\% 83$ \\
\hline & & Dâhil değil & Dâhil değil & $118.5 \mathrm{~s}$ & 0 \\
\hline \multirow{3}{*}{$\begin{array}{c}\text { \%10 Tuz ve biber } \\
\text { gürültüsü eklenmiş } \\
\text { 512x512 Lena Görüntüsü }\end{array}$} & \multirow{3}{*}{9.7} & Dâhil & Dâhil & $19.0 \mathrm{~s}$ & $\% 83$ \\
\hline & & Dâhil & Dâhil değil & $18.9 \mathrm{~s}$ & $\% 83$ \\
\hline & & Dâhil değil & Dâhil değil & $113.3 \mathrm{~s}$ & 0 \\
\hline \multirow{3}{*}{$\begin{array}{c}\text { \%30 Tuz ve biber } \\
\text { gürültüsü eklenmiş } \\
\text { 512x512 Lena Görüntüsü }\end{array}$} & \multirow{3}{*}{5.1} & Dâhil & Dâhil & $17.9 \mathrm{~s}$ & $\% 82$ \\
\hline & & Dâhil & Dâhil değil & $18.0 \mathrm{~s}$ & $\% 82$ \\
\hline & & Dâhil değil & Dâhil değil & $101.6 \mathrm{~s}$ & 0 \\
\hline
\end{tabular}




\section{Sonuç}

Şekil 8, 9, 10 ve 11'de farklı tuz ve biber oranlarında kenar bulma yöntemlerinin test sonuçları gösterilmektedir. Gürültü oranı arttıç̧a SGO değerinin azaldığı tespit edilmiştir. Canny, Sobel ve Roberts tuz ve biber gürültüsü eklenmiş görüntülerde iyi sonuç vermemektedir. Bu üç yöntemde gürültü oranı arttıkça detaylar bozulmaktadır. Gürültü oran $1 \% 30$ seviyesinde iken detaylar belli bir ölçüde BK veya KDK kullanılarak tespit edilmiştir fakat detaylar tamamen belirgin değildir. Durulaştırma sonuçlarında ise gürültünün bozucu etkisi görülmektedir. $\mathrm{Bu}$ gürültü seviyesinde Canny, Roberts ve Sobel yöntemlerinde detaylar tamamen kaybolmaktadır. Bulanık kuralların kullanılmasıyla daha az gürültü seviyelerinde detaylar daha iyi tespit edilmekte ve gürültüden fazla etkilenmeden kenarlar bulunabilmektedir. Denemeler bu yöntemin tuz ve biber gürültüsü içeren görüntülerde Canny, Sobel ve Roberts'e göre başarılı sonuçlar verdiğini göstermektedir. Bu çalışmada iki geliştirme önerilmektedir. İlk geliştirmede MEBY ile tüm entropileri hesaplanmak yerine belirli aralıklarla hesaplama yapılmaktadır. Tablo 2'de ifade edildiği gibi MEBY ile programın çalışma sürelerinde \%83 civarında bir kazanım söz konusudur. Diğer geliştirme ile SGO kullanılarak görüntü için bir eşik değer belirlenmektedir. Bu eşik değerin üstünde olan görüntülerde $\mathrm{BK}$, altında olan görüntülerde KDK kullanılmaktadır. Gürültü oranı \%1'in altında ya da sıfıra yakın olduğu durumlarda SGO ile yapılan seçim çalışma süresini azaltmaktadır. Gürültüsü az olan görüntü için çalışma süresinde \%6 civarında bir kazanım söz konusudur. Bu iki geliştirme programın çalışma süresini önemli ölçüde azaltmıştır.

\section{Kaynaklar}

[1] Nallaperumal K., Varghese J., Saudia S., Krishnaveni K., Mathew S.P. ve Kumar P., An efficient Switching Median Filter for Salt Pepper Impulse Noise Reduction, 2006 1st International Conference on Digital Information Management, 161-166, (2007).

[2] Hu, L., Cheng, H. D. ve Zang, M., A high performance edge detector based on fuzzy inference rules, An International Journal on Information Sciences, 177, 21, 4768-4784, (2007).

[3] Pitas, I. ve Venetsanopou, N., Nonlinear Digital Filters: Principles and Application, 243, Springer, (1990).

[4] Premchaiswadi, N., Yimngam S. ve Premchaiswadi, W., A Scheme for Salt and Pepper Noise Reduction on Graylevel and Color Images, Proceedings of the 9th WSEAS International Conference on Signal Processing, Computational Geometry and Artificial Vision, 57-61, (2009).

[5] Chinnasarn K., Rangsanseri, Y. ve Thitimajshima, P., Removing salt and pepper noise in text/graphics images, Circuits and Systems, 1998. IEEE APCCAS 1998. The 1998 IEEE Asia-Pacific Conference on, 459-462, (1998).

[6] http://web.firat.edu.tr/iaydin/bmu357/bmu357_bolum_5.pdf, (24.03.2017).

[7] https://en.wikipedia.org/wiki/Median_filter, (24.03.2017).

[8] Changhong W., Taoyi C. ve Zhenshen Q., A novel improved median filter for salt-and-pepper noise from highly corrupted images, 2010 3rd International Symposium on Systems and Control in Aeronautics and Astronautics, 718722, (2010). 
[9] Zhou Y., Tang Q.H. ve Jin W.D., Adaptive Fuzzy Median Filter for Images Corrupted by Impulse Noise, 2008 Congress on Image and Signal Processing, 265-269, (2008).

[10] Palabaş T. ve Gangal A., Adaptive fuzzy filter combined with median filter for reducing intensive salt and pepper noise in gray level images, 2012 International Symposium on Innovations in Intelligent Systems and Applications, 1-4, (2012).

[11] Singh S. ve Singh B., Effects of noise on various edge detection techniques, Computing for Sustainable Global Development (INDIACom), 2015 2nd International Conference, 827-830, New Delhi, (2015).

[12] https://tr.wikipedia.org/wiki/Bulanık_mantık, (24.03.2017).

[13] Russo F. ve Ramponi G., Edge extraction by FIRE operators, Proceedings of the Third IEEE International Conference on Fuzzy Systems, 249-253, (1994).

[14] Shannon C.E., "A mathematical theory of communication," The Bell System Technical Journal, vol. 27, no. 3, pp. 379-656, (1948).

[15] Gonzalez, C.F. veWoods, R. E., Digital Image Processing, 231, Pearson, (2007).

[16] Baykal, N. ve Beyan, T., Bulanık mantık ilke ve temelleri, 383-385, Biçaklar Kitabevi, (2004).

[17] Pfluger N., Yen J. ve Langari R., A defuzzification strategy for a fuzzy logic controller employing prohibitive information in command formulation, [1992 Proceedings] IEEE International Conference on Fuzzy Systems, 717-723, San Diego (1992). 